\title{
Waste Polyethylene Terephthalate as an Aggregate in Concrete
}

\author{
Nabajyoti Saikia ${ }^{\mathrm{a}, \mathrm{b}}$, Jorge de Brito ${ }^{\mathrm{a} *}$ \\ a'Department of Civil Engineering, Architecture and Georesources, Instituto Superior Técnico, \\ Technical University of Lisbon, Av. Rovisco Pais, 1049-001 Lisbon, Portugal \\ ${ }^{\mathrm{b}}$ Faculty of Science and Technology, Kaziranga University, Koraikhowa, Jorhat-785006, Assam, India
}

Received: August 27, 2012; Revised: November 6, 2012

This paper reports the strength behaviour of concrete containing three types of recycled polyethylene terephthalate (PET) aggregate. Results are also analysed to determine the PET-aggregate's effect on the relationship between the flexural and splitting tensile strengths and compressive strength and to know whether the relationships between compressive strength and other strength characteristics given in European design codes are applicable to concrete made with PET-aggregates. The compressive strength development of concrete containing all types of PET-aggregate behaves like in conventional concrete, though the incorporation of any type of PET-aggregate significantly lowers the compressive strength of the resulting concrete. The PET-aggregate incorporation improves the toughness behaviour of the resulting concrete. This behaviour is dependent on PET-aggregate's shape and is maximised for concrete containing coarse, flaky PET-aggregate. The splitting tensile and flexural strength characteristics are proportional to the loss in compressive strength of concrete containing plastic aggregates.

Keywords: waste PET bottle, aggregate, concrete

\section{Introduction}

The consumption of plastic has grown substantially all over the world in recent years and this has created huge quantities of plastic-based waste. Plastic waste is now a serious environmental threat to the modern way of living. In Portugal, post-consumer packaging accounts for almost $40 \%$ of total domestic waste and it is therefore an important source for the recycled materials market ${ }^{1}$. In a typical Portugal municipality about $10-14 \%$ of all generated waste is plastic $^{1}$. Plastic waste cannot be dumped in landfills because of its bulk and slow degradation rate. Recycling plastic waste to produce new materials like aggregate in concrete could be one of the best solutions for disposing of it, given its economic and ecological advantages. The European aggregates demand is 3 billion tons per year, representing a turnover of around $€ 20$ billion. Some $90 \%$ of all aggregates are produced from natural resources. The other $10 \%$ come from recycled aggregates (6\%), and marine \& manufactured aggregates ( $2 \%$ each). Naturally, the use of waste materials as aggregate in concrete production will reduce the pressure on the exploitation of natural resources.

Plastic aggregate (PA) is produced by mechanically separating and processing plastic waste. A life cycle analysis of mixed household plastics shows that mechanical recycling provides a higher net positive environmental impact than the recovery of energy or land-filling ${ }^{2-4}$. Different types of plastic waste have been used as aggregate, filler or fibre in cement mortar and concrete after mechanical treatment. They include: polyethylene terephthalate (PET) bottles, polyvinyl chloride, PVC pipes, high density polyethylene, HDPE, thermosetting plastics, mixed plastic waste, expanded

*e-mail: jb@ civil.ist.utl.pt polystyrene foam, polyurethane foam, polycarbonate, and glass reinforced plastic ${ }^{5-21}$. The details about the generation of PA as well as the properties of concrete containing PA are presented in a recent review ${ }^{22}$.

The incorporation of PA can significantly improve some properties of concrete because plastic has high toughness, good abrasion behaviour, low thermal conductivity and high heat capacity ${ }^{23-25}$. PA is significantly lighter than natural aggregate (NA) and therefore its incorporation lowers the densities of the resulting concrete ${ }^{22,26}$. This property can be used to develop lightweight concrete. The use of shredded waste PA in concrete can reduce the dead weight of concrete, thus lowering the earthquake risk of a building, and it could be helpful in the design of an earthquake-resistant building ${ }^{6}$.

However incorporation of PA in concrete has several negative effects such as poor workability and deterioration of mechanical behaviour ${ }^{22,26}$. The strength properties and modulus of elasticity of concrete containing various types of PA are always lower than those of the corresponding reference concrete containing NA only. The decrease in bond strength between PA and cement paste as well as the inhibition of cement hydration due to the hydrophobic nature of plastic are the reasons for the poor mechanical properties of concrete containing plastic. Treating plastic chemically and coating plastics with slag and sand powders can improve the mechanical performance of concrete by improving the interaction between cement paste and $\mathrm{PA}^{14,27,28}$. The prolonged curing of PET fibre in simulated cement pore-fluid can initiate the alkaline hydrolysis of PET, and form some organic compounds, which may increase the interaction between plastic aggrgate and cement hydration products $^{29}$. 
However, the information available on the use of plastic waste as aggregate in concrete is not always adequate. For example, the workability behaviour of concrete containing similar type of PA is reported to be contradictory in different references ${ }^{22,26}$. The shape and size of the aggregate have a significant influence on both fresh and hardened concrete properties. No thorough study is available on the effect of the shape of PA on the properties of the resulting concrete.

Further research to evaluate plastic waste as an aggregate in concrete production is therefore required. This is the background to the work reported here, in which three types of recycled polyethylene terephthalate aggregate (PETaggregate) of differing sizes and shapes were considered so as to understand how its size and shape influences the behaviour of the resulting concrete. The development of compressive strength, the most important concrete property is analysed along with the relative tensile and flexural strength, with reference to compressive strength. The results are then analysed using the present Eurocode 2 and the European EN 206 standard specifications.

\section{Material and Methods}

The plastic waste used as aggregate was collected from a plastic recycling plant in Portalegre, Portugal. The plant mainly recycles post-consumer PET bottles collected as compressed bales (Figure 1) that come from urban and industrial collection sites. The bales of PET-waste mostly consist of dirty PET-bottles, which are usually contaminated with other materials and with some non-PET containers such as PVC, HDPE and poly propylene, bottles. The composition of a typical waste plastic raw material is presented in Table 1.

In this plastic waste treatment plant, several steps are adopted to recycle waste plastic. The coarse flakes and fine fractions were obtained after mechanical grinding of PET wastes followed by cleaning and separation by

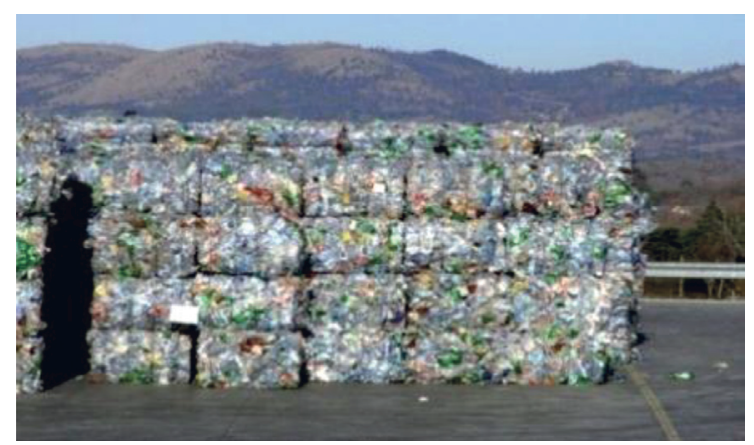

Figure 1. Compressed bales of waste plastic bottles.

Table 1. Composition of typical waste plastic raw materials.

\begin{tabular}{lc}
\hline \multicolumn{1}{c}{ Type of material } & Mass $(\%)$ \\
\hline PET packaging (with label, cover, etc.) & $\geq 96$ \\
PVC contaminant & $\leq 0.5$ \\
Hazardous Waste & 0 \\
Polyethylene + Polypropylene & $\leq 0.25$ \\
Metals, wood, ceramic, glass & 0 \\
Other (unspecified) & $<4$ \\
\hline
\end{tabular}

physico-chemical methods. The plastic pellet is produced from plastic flakes. This material consists of predefined and even-sized PET-grains, free of contamination at the microscopic level.

For production of pellets, the flakes of PET are dosed to a reactor through a system capable of maintaining a vacuum in the reactor by using a dosing screw, according to predetermined conditions. The vacuum obtained is less than 10 mbar. The reactor is equipped with an agitation system that, by friction, promotes heating of the material to the drying temperature. The agitation system has three floors, which ensure uniform and gradual warming of the material to extrude. Feeding of the extruder is made through a window with a slider that controls the amount of material allowed.

The heated material is extruded through an extruder spindle, with a polymer filter and a spinneret with holes. The heating and melting of the heated material is performed in vacuum, which allows the extraction of volatile contaminants. The extrusion process is relatively short, which limits the occurrence of secondary reactions during the melting stage. After passing through a spinneret,

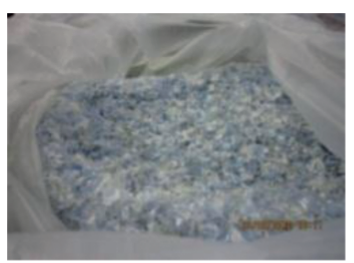

(a)

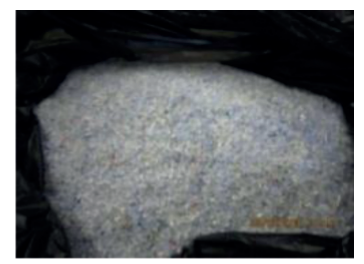

(b)

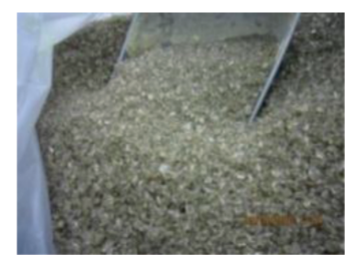

(c)

Figure 2. PET aggregates used in this investigation: (a) PC; (b) PF; (c) PP.

Table 2. Sieve analysis of various PET-aggregates.

\begin{tabular}{crrr}
\hline \multirow{2}{*}{$\begin{array}{c}\text { Sieve size } \\
(\mathbf{m m})\end{array}$} & \multicolumn{3}{c}{ Cumulative amount passed $(\boldsymbol{\%})$} \\
\cline { 2 - 4 } & \multicolumn{1}{c}{ PC } & \multicolumn{1}{c}{ PF } & PP \\
\hline 16.0 & 100.00 & 100.00 & 100.00 \\
11.2 & 99.96 & 100.00 & 100.00 \\
8.0 & 97.69 & 100.00 & 100.00 \\
5.6 & 49.24 & 100.00 & 100.00 \\
4.0 & 20.59 & 99.99 & 99.46 \\
2.0 & 0.89 & 45.65 & 7.93 \\
1.0 & 0.02 & 0.94 & 0.04 \\
0.5 & 0.00 & 0.01 & 0.02 \\
0.25 & 0.00 & 0.00 & 0.00 \\
0.125 & 0.00 & 0.00 & 0.00 \\
0.063 & 0.00 & 0.00 & 0.00 \\
Residue & 0.00 & 0.00 & 0.00 \\
\hline
\end{tabular}


Table 3. Properties of the aggregates.

\begin{tabular}{|c|c|c|c|c|c|c|}
\hline \multirow[t]{2}{*}{ Property } & \multirow[t]{2}{*}{ Method used } & \multicolumn{5}{|c|}{ Results } \\
\hline & & $\mathbf{C A}$ & FA & PC & $\mathbf{P F}$ & $\mathbf{P P}$ \\
\hline SSD basis $\left(\mathrm{kg} \cdot \mathrm{m}^{-3}\right)$ & EN 1097-6 & 2606 & 2643 & 1344 & 1344 & 1344 \\
\hline Water absorption dry basis, $24 \mathrm{~h}(\%)$ & EN 1097-6 & 0.63 & 0.20 & 0.18 & 0.25 & 0.10 \\
\hline Bulk density & ASTM C 29/C 29M-97 & 1418 & 1441 & 351 & 555 & 827 \\
\hline
\end{tabular}

SSD: saturated surface dry; CA: coarse natural aggregate; FA: fine natural aggregate.

Table 4. Concrete mix composition.

\begin{tabular}{|c|c|c|c|c|c|c|c|c|}
\hline \multirow{2}{*}{$\begin{array}{c}\text { Concrete } \\
\text { mixes }\end{array}$} & \multirow{2}{*}{$\begin{array}{l}\text { Cement } \\
\left(\mathrm{kg}^{\left.-m^{-3}\right)}\right.\end{array}$} & \multirow{2}{*}{$\begin{array}{c}\text { Water } \\
\left(\mathrm{kg}^{\left.-m^{-3}\right)}\right.\end{array}$} & \multicolumn{5}{|c|}{ Aggregate $\left({\left.\mathrm{kg} . \mathrm{m}^{-3}\right)}^{-3}\right.$} & \multirow[t]{2}{*}{$\mathbf{W} / \mathbf{C}$} \\
\hline & & & Coarse & Fine & $\mathbf{P C}$ & $\mathbf{P F}$ & $\mathbf{P P}$ & \\
\hline Ref & 350 & 185.5 & 996.4 & 802.7 & - & - & - & 0.53 \\
\hline PC5 & 350 & 213.5 & 920.4 & 788.4 & 45.9 & - & - & 0.61 \\
\hline $\mathrm{PC} 10$ & 350 & 227.5 & 844.5 & 774.1 & 91.7 & - & - & 0.65 \\
\hline $\mathrm{PC} 15$ & 350 & 259.0 & 768.5 & 759.8 & 137.5 & - & - & 0.74 \\
\hline PF5 & 350 & 199.5 & 996.4 & 713.3 & - & 45.9 & - & 0.57 \\
\hline PF10 & 350 & 210.0 & 996.4 & 624.0 & - & 91.7 & - & 0.60 \\
\hline PF15 & 350 & 224 & 996.4 & 534.6 & - & 137.5 & - & 0.64 \\
\hline PP5 & 350 & 185.5 & 996.4 & 713.3 & - & - & 45.9 & 0.53 \\
\hline PP10 & 350 & 182 & 996.4 & 624.0 & - & - & 91.7 & 0.52 \\
\hline PP15 & 350 & 182 & 996.4 & 534.6 & - & - & 137.5 & 0.52 \\
\hline
\end{tabular}

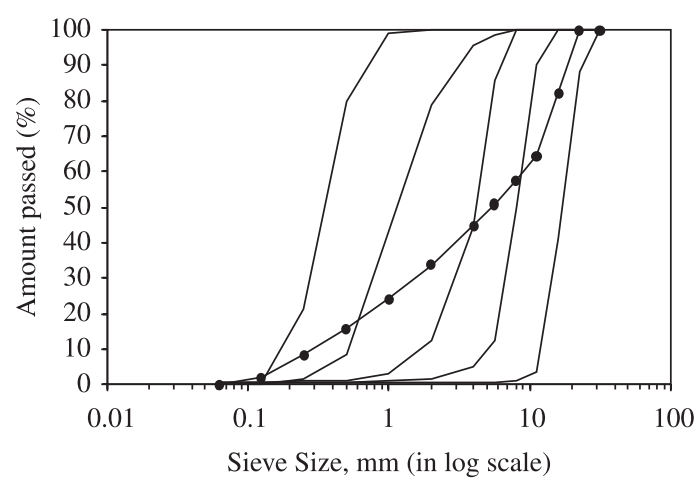

Figure 3. Faury grading curve (with markers) and the grading size distribution curves of NA.

the melt is collected in a cooling bath that solidifies the polymer before being granulated in a rotary cutter in water. The mixture of water and grains of polymer is subjected to a vibratory separator and then the grains of polymer are centrifuged to remove excess water. The plastic pellets are then pneumatically transported to the weighing system and then to a packaging station.

The coarse flakes (PC), fine fraction (PF) and the plastic pellets (PP) are used as plastic aggregate in the preparation of structural concrete and depicted in Figure 2. No further crushing of the PET-aggregates was done in the laboratory. The sieve analysis of the PET-aggregates was carried out according to method NP EN 933-2 and is presented in Table 2. CEM II A-L42.5 R type cement was used in this work. Calcareous natural coarse aggregates of three different size ranges and quartzite natural fine aggregates of two different size ranges were used throughout.
The experimental methods used to determine various aggregate properties and results are presented in Table 3. The concrete mixes were prepared by the same method, which requires using exactly the same aggregate grading curve and concrete composition in terms of cement content, coarse and fine aggregate quantities and slump value. The differences between the various mixes are thus reduced solely to the coarse aggregates' nature. The Faury aggregate grading curve presented in Figure 3 was used in this work. It also shows the grading size distribution of the natural aggregates (NA), determined using NP EN 933-2. All types of aggregate were therefore separated into different size fractions by mechanical sieving.

A total of nine concrete mixes containing three types of PET-aggregate, plus one reference concrete (exclusively with NA) mix, were prepared for a constant range of slump 120-135 mm (Table 4). Three sub-classes of concrete mixes were prepared by replacing 5\%,10\% and $15 \%$ volume of NA by equal volumes of each type of PET-aggregate. The preparation of concrete mixes, their casting and the evaluation of their properties followed standard procedures. The different test methods used to determine fresh and hardened state concrete properties are presented in Table 5. Results for all mechanical properties are the average of three specimens.

\section{Results and Discussion}

\subsection{Mechanical behaviour}

The development of compressive strength of the reference concrete and of those containing the three types of PET-aggregates in varying amounts is presented in Figure 4. The 7, 28 and 91-day compressive strengths $\left(f_{\mathrm{cm}}\right)$, 
Table 5. Experimental methods used to evaluate concrete.

\begin{tabular}{ll}
\hline \multicolumn{1}{c}{ Targeted properties } & \multicolumn{1}{c}{ Method } \\
\hline Fresh concrete & \\
Slump test & NP EN 12350-2 \\
Density & NP EN 12350-6 \\
Hardened concrete & \\
Compressive strength & NP EN 12390-3 \\
Splitting tensile strength & NP EN 12390-6 \\
Flexural strength & NP EN 12390-5 \\
Water absorption capacity & LNEC E 394 \\
\hline
\end{tabular}
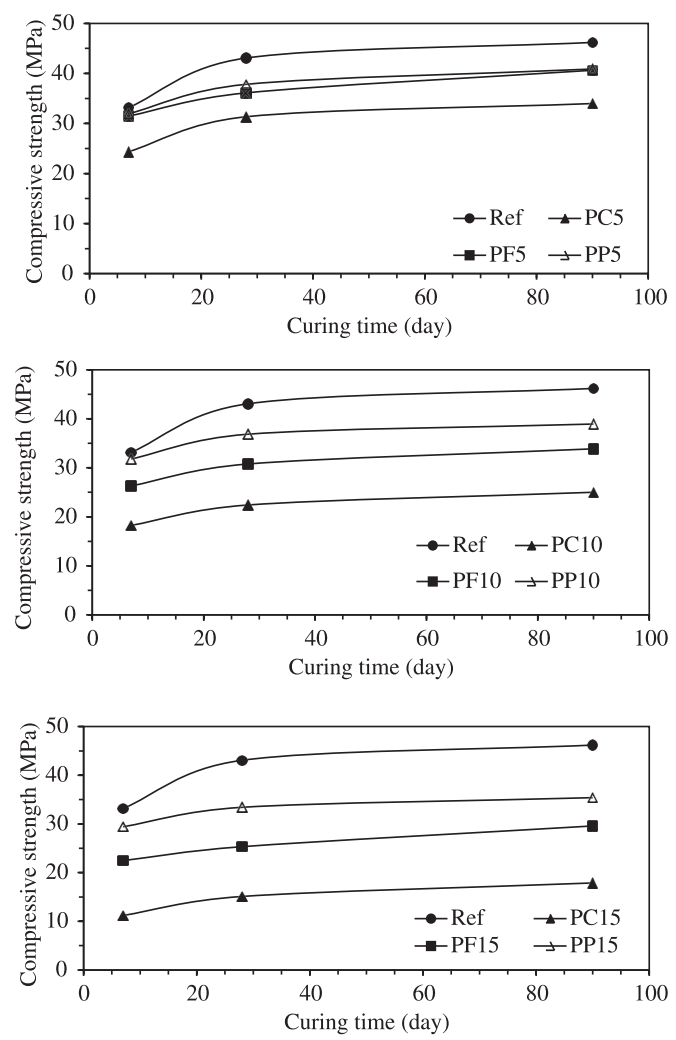

Figure 4. Development of compressive strength of various concretes with increasing curing time. standard and average deviations ( $\mathrm{S}_{\mathrm{dev}}$ and $\mathrm{A}_{\mathrm{dev}}$ respectively) of concrete with plastic aggregate as a substitution of 0 (reference), 5\%,10\% and 15\% natural aggregate are given in Table 6 .

The figure indicates that the development of compressive strength of concrete containing all types of PET-aggregate follows a similar behaviour to conventional concrete, although the incorporation of any type of PET-aggregate significantly lowers the compressive strength of the resulting concrete. The increase of compressive strength in the initial curing period ( 0 to 28 days) is substantially higher than that for later curing periods. However, a significant proportion of the reduction in strength of the PC and PF mixes compared to the control is due to the increased water to cement ratio necessary to maintain slump (Table 4). The 28-day compressive strength is near the figures for 91 days in most cases, since it is known that concrete almost reaches its full strength during the first 28 days of curing. Albano et al. and Frigione et al. report similar observations for concrete containing PET-aggregates ${ }^{5,7}$.

Figure 5 shows the relative strength of all types of concrete with respect to the strength of the 91-day concrete for different percentages of substitution. It appears that the early strength gain trend of concrete prepared with $15 \%$ volume replacement of NA by PC (PC15) with respect to 91-day strength is slightly different from the equivalent trend for concrete made with $5 \%$ and $10 \%$ replacement (PC5 and PC10). The trends followed by PP and PF for all substitution levels are almost identical, however. The 7-day compressive strength of PC15 is low compared to its 91-day strength. After 28 days of curing it gains substantial strength but is still lower than the other types of concrete. The 7-day relative compressive strength of concrete containing PP and $\mathrm{PF}$ at all substitution levels is considerably higher than that for the control concrete specimens, and it is highest for concrete containing 15\% PP-aggregate (PP15).

The possible reason for the early strength gain for most of the concretes containing PET-aggregate is the low thermal conductivity of PET-aggregate. The low thermal conductivity may reduce the heat loss and therefore increase the temperature rise during hydration of cement pastes, which ultimately increases the strength of concrete

Table 6. Compressive strength of concrete with various percentages of replacement of natural aggregates (NA) by plastic aggregates.

\begin{tabular}{|c|c|c|c|c|c|c|c|c|c|c|}
\hline \multirow{2}{*}{$\begin{array}{c}\% \text { of } \\
\text { substitution }\end{array}$} & \multirow{2}{*}{$\begin{array}{c}\text { Type of } \\
\text { aggregate }\end{array}$} & \multicolumn{3}{|c|}{7 days } & \multicolumn{3}{|c|}{28 days } & \multicolumn{3}{|c|}{91 days } \\
\hline & & $\underset{(\mathbf{M P a})}{f_{\mathrm{cm}}}$ & $\underset{(\mathbf{M P a})}{\mathbf{S}_{\mathrm{dev}}}$ & $\begin{array}{c}\mathbf{A}_{\mathrm{dev}} \\
(\mathbf{M P a})\end{array}$ & $\underset{(\mathbf{M P a})}{f_{\mathrm{cm}}}$ & $\underset{(\mathbf{M P a})}{\mathbf{S}_{\mathrm{dev}}}$ & $\begin{array}{c}\mathbf{A}_{\mathrm{dev}} \\
(\mathbf{M P a})\end{array}$ & $\underset{(\mathbf{M P a})}{f_{\mathrm{cm}}}$ & $\underset{(\mathbf{M P a})}{\mathbf{S}_{\mathrm{dev}}}$ & $\begin{array}{c}\mathbf{A}_{\mathrm{dev}} \\
(\mathbf{M P a})\end{array}$ \\
\hline 0 & Normal & 33.18 & 0.269 & 0.204 & 43.07 & 0.091 & 0.066 & 46.19 & 0.198 & 0.136 \\
\hline \multirow[t]{3}{*}{5} & PC & 24.37 & 0.481 & 0.349 & 31.34 & 0.253 & 0.187 & 33.98 & 0.479 & 0.361 \\
\hline & $\mathrm{PF}$ & 31.48 & 1.085 & 0.740 & 36.11 & 0.204 & 0.156 & 40.63 & 0.446 & 0.338 \\
\hline & PP & 31.95 & 0.785 & 0.532 & 37.82 & 1.06 & 0.779 & 40.88 & 0.694 & 0.521 \\
\hline \multirow[t]{3}{*}{10} & $\mathrm{PC}$ & 18.25 & 0.802 & 0.615 & 22.42 & 0.964 & 0.724 & 25.01 & 0.830 & 0.569 \\
\hline & $\mathrm{PF}$ & 26.32 & 0.825 & 0.593 & 30.79 & 0.994 & 0.674 & 33.87 & 0.301 & 0.214 \\
\hline & PP & 31.81 & 0.703 & 0.482 & 36.86 & 0.498 & 0.342 & 38.93 & 0.318 & 0.237 \\
\hline \multirow[t]{3}{*}{15} & $\mathrm{PC}$ & 11.20 & 1.081 & 0.823 & 15.10 & 1.070 & 0.821 & 17.88 & 0.845 & 0.595 \\
\hline & $\mathrm{PF}$ & 22.47 & 0.962 & 0.738 & 25.33 & 0.798 & 0.561 & 29.59 & 0.927 & 0.630 \\
\hline & PP & 29.43 & 0.695 & 0.478 & 33.41 & 0.610 & 0.419 & 35.40 & 0.819 & 0.562 \\
\hline
\end{tabular}


specimens. Kan and Demirboga also observed a substantial strength gain in concrete containing modified expanded polystyrene aggregate (MEPS) in the early curing periods ${ }^{18}$. The authors stated that the lower specific thermal capacity of MEPS-aggregate resulted in a reduced heat loss from
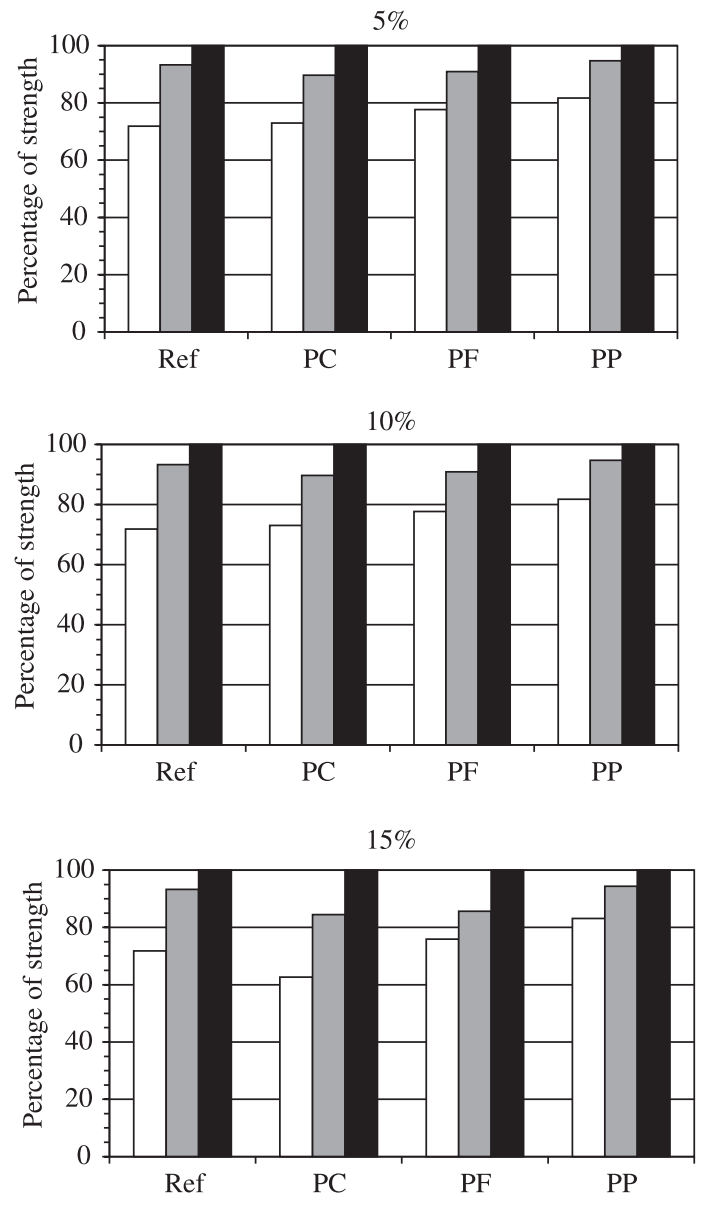

$\square$ 7-day $\square$ 28-day $\square$ 91-day

Figure 5. Percentage of 7- and 28-day compressive strength of concrete containing PET aggregates and the reference concrete with respect to the 91-day strength for different percentages of substitution.

Table 7. Splitting tensile strength (TS) and flexural strength (FS) to compressive strength (CS) ratios.

\begin{tabular}{ccc}
\hline Concrete type & TS/CS & FS/CS \\
\hline Ref & 0.081 & 0.110 \\
PC5 & 0.088 & 0.124 \\
PC10 & 0.102 & 0.138 \\
PC15 & 0.121 & 0.158 \\
PF5 & 0.085 & 0.118 \\
PF10 & 0.092 & 0.122 \\
PF15 & 0.090 & 0.118 \\
PP5 & 0.085 & 0.120 \\
PP10 & 0.085 & 0.115 \\
PP15 & 0.086 & 0.119 \\
\hline
\end{tabular}

the concrete, thereby increasing the heat of hydration. However, less strength gain in the early period for PC15 is unknown, though the very high w/c ratios (Table 4) might have some effect.

Substantial reductions in other strength properties (splitting tensile strength, TS and flexural strength, FS) were also observed for all substitution patterns as the percentage of PET-aggregate incorporated increased. The reason is basically similar to that given in almost all studies related to plastic aggregate incorporating concrete: the weak interfacial binding between the plastic aggregate and cement paste.

\subsection{Relationship of compressive strength with other properties}

The ratio between the tensile and compressive strength can give information on the toughness behaviour of concrete specimen $^{30}$. Concrete of higher toughness exhibits higher values of this ratio. The tensile/compressive strength and flexural/compressive strength ratios are therefore determined and presented in Table 7 . The ratios between the tensile and compressive strengths observed for all PET-aggregate containing specimens are higher than that for conventional concrete, and the value increases with PET content. Thus

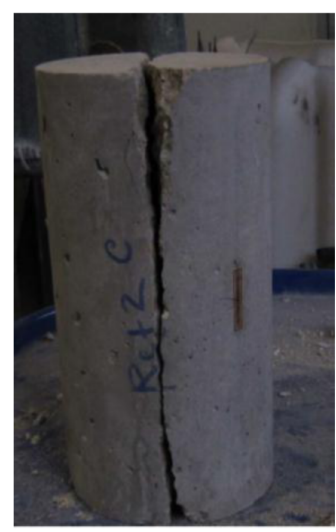

(a)

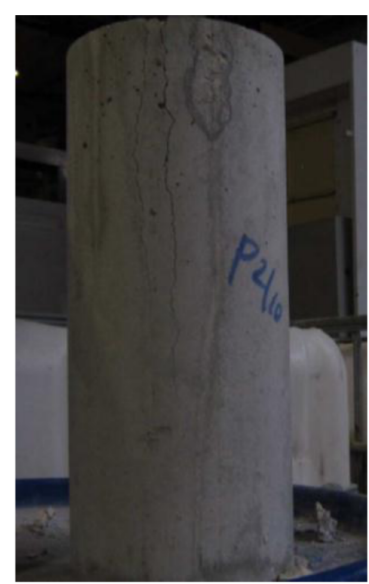

(c)

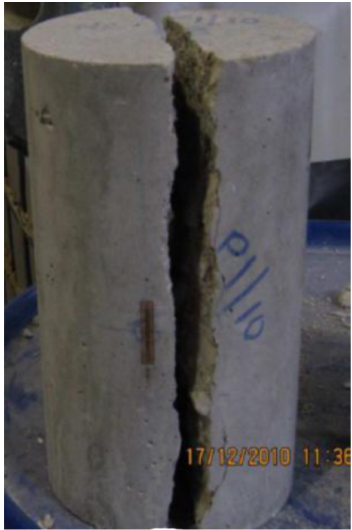

(b)

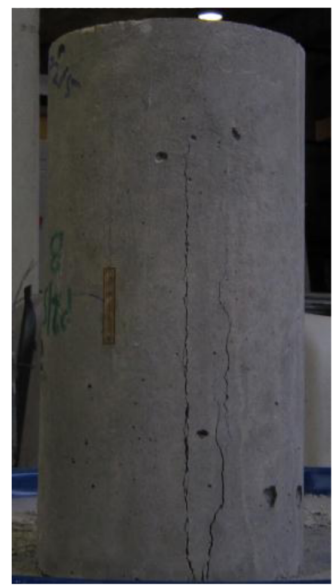

(d)
Figure 6. Concrete specimens after determinations of tensile splitting strength: (a) Reference; (b) PP10; (c) PF10; (d) PC5. 
incorporation of PET-aggregate in concrete mixes increases the toughness behaviour. For a particular amount of PETaggregate addition, this order can be arranged as: $\mathrm{PC}>\mathrm{PF}$ $>$ PP, which indicates that the large-flake PET-aggregates can have more effect on improving the toughness behaviour of resulting concrete than the other two fractions. The ratio between flexural and compressive strength behaves like the ratio between tensile and compressive strength.

Figure 6 shows the specimens after failure during the tensile strength determination of various concrete specimens. The presence of PF at $10 \%$ and $15 \%$ substitution levels and $\mathrm{PC}$ at all substitution levels in the concrete specimens prevented them from suddenly separating into two pieces, as was generally observed in the reference concrete, in the specimens containing PP for all substitution levels and in PF for $5 \%$. Thus concrete specimens with PET-aggregate are able to withstand additional loading after they crack. This is perceptibly more pronounced for concrete containing flaky PET-aggregates, where the specimens do not physically separate into two pieces under loading, possibly due to the bridging of cracks by PET-particles. Concrete containing flaky PET-aggregate may be able to do this better than that containing PET-pellet because of the differences in their load
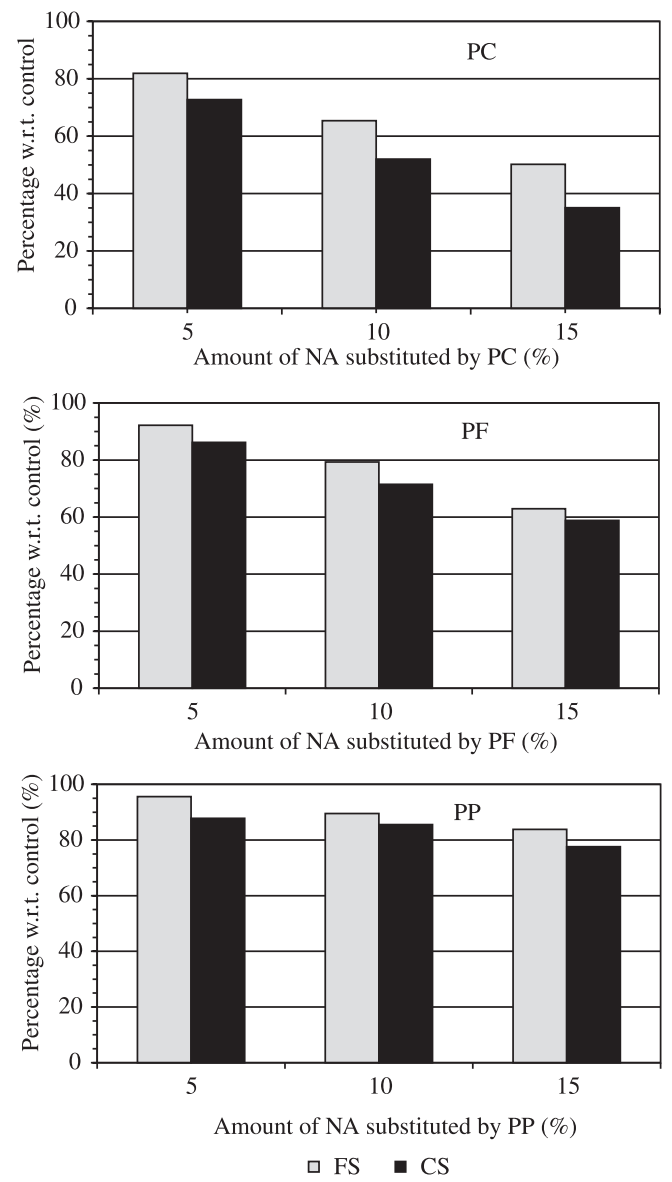

Figure 7. Percentage reduction of flexural strength (FS) with compressive strength (CS) reduction in various other concrete with respect to the reference concrete. transfer ability. Once debonded from the concrete matrix pellets are too short to transfer the applied load through interfacial frictional force, whereas flakes are longer and can transfer the applied load ${ }^{31}$.

The percentage reduction of compressive strength was also compared with the percentage reductions of flexural strength with respect to the reference concrete, as presented in Figure 7. As in the Hannawi et al. study (2010), the reduction in compressive strength with respect to the reference concrete was greater than the reduction observed in the flexural strength ${ }^{8}$. This difference is more pronounced for concrete with PC, which is coarser and flakier than the other two PET-aggregates. Incorporating PET-aggregate in concrete thus improves the relative flexural strength behaviour. The observed results also suggest that the flexural behaviour is dependent on the size and shape of the PETaggregate. Regardless of the type of plastic, the correlations between the 28-day splitting tensile and flexural strengths (represented in X-axis) and the 28-day compressive strength (represented in Y-axis) can be presented by following linear Equations 1 and 2 respectively:

$Y=11.618 X+0.9101 ; R^{2}=0.980$

$$
Y=10.888 X-9.9961 ; R^{2}=0.973
$$

Figure 8 shows the relationship between 28-day compressive strengths (represented in Y-axis) and corresponding dry densities (represented in $\mathrm{X}$-axis) of concrete specimens. It can be seen that the decrease in dry density of concrete specimens is associated with the decrease of its compressive strength. It should also be mentioned that increasing the content of all types of PET-aggregate in

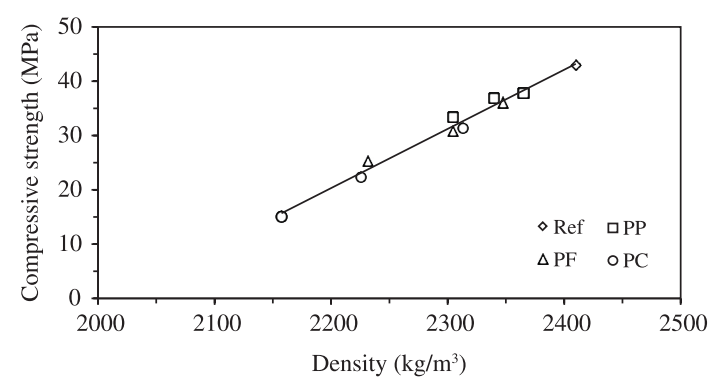

Figure 8. Relationship between 28-day dry density and compressive strength.

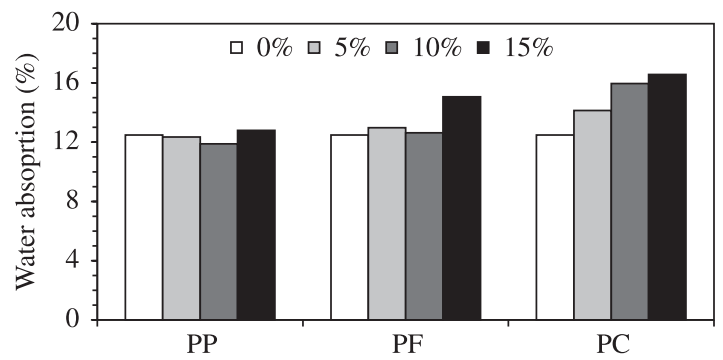

Figure 9. Water absorption capacity of concrete containing various amounts of PET aggregate. 
concrete lowers its dry density. Regardless of the type of plastic, the following linear relationship can be proposed to correlate dry density with compressive strength:

$Y=0.1091 X-219.71 ; R^{2}=0.983$

\subsection{Water absorption behaviour}

The 28-day water absorption capacities of concrete specimens containing the different PET-aggregates at various replacement levels are presented in Figure 9. The results reveal that the incorporation of PP-aggregate at all replacement levels and PF-aggregate at 5 and $10 \%$ replacement levels do not have too much influence on the water absorption behaviour of the resulting concrete. In fact, incorporating PP-aggregate up to $10 \%$ replacement level lowers the water absorption capacity of the concrete specimen. But the water absorption capacity of concretes containing $15 \%$ PF-aggregate replacement and PC aggregate at all replacement levels is higher than the normal concrete. For PC-aggregate, water absorption increases with higher replacement levels.

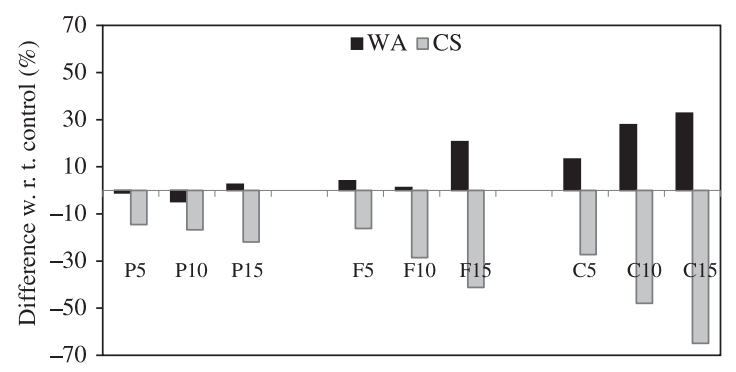

Figure 10. Percentage reduction of water absorption (WA) and compressive strength (CS) of various other concrete with respect to the reference concrete.

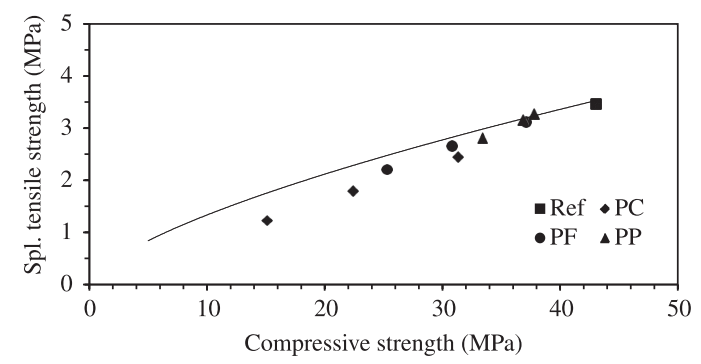

(a)

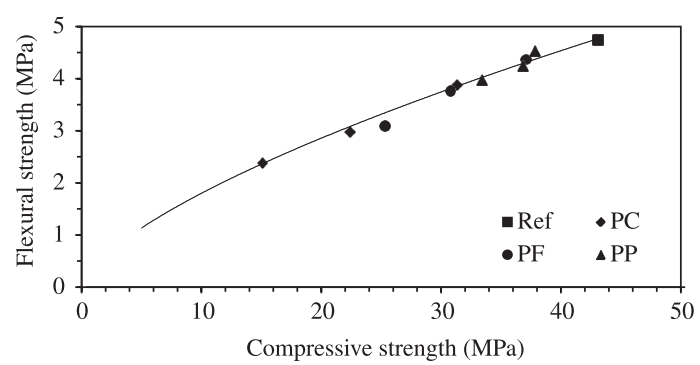

(b)

Figure 11. Cubic compressive strength versus (a) tensile strength; (b) flexural strength (the solid line is obtained using the EC2 expression).
The differences in percentage of compressive strengths and water absorption capacities of concrete containing various types of PET-aggregates from the control mix are presented in Figure 10. The positive and negative values on the Y-axis respectively indicate the increasing and decreasing percentage amount of these parameters with respect to the amount for the reference concrete. The decreasing percentage of compressive strength for concretes containing $15 \%$ PF replacement and the concrete containing $\mathrm{PC}$-aggregate at all replacement levels is due to the higher porosity of these concretes, as higher water absorption generally indicates higher porosity. But the reduction in the compressive strength of concretes containing PP-aggregate at all replacement levels, as well as the concrete containing PF-aggregate at 5 and $10 \%$ replacement levels, cannot be related to the water absorption capacity of these concrete compositions as the later values nearly the same or better than that of the reference. This indicates that another factor such as PET-aggregate to cement paste binding is also responsible for the strength reduction of concrete containing PET-aggregate.

\subsection{Analysis of results using Eurocode 2}

In spite of limitations such as restricted amounts of experimental data and minimum variations of experimental conditions, the experimental results are analysed using the existing Eurocode 2 (EC 2004), as explained below ${ }^{32}$.

According to Eurocode 2 (EC2), the relationship between mean cubic compressive strength $\left(f_{c m}\right)$ and characteristic cylindrical compressive strength $\left(f_{c k}\right)$ can be expressed by ${ }^{33}$ :

$f_{c m}=1.25 \cdot f_{c k}$

According to this relationship, the 28-day cylindrical compressive strength of the reference concrete should be around 34.46 MPa. Again from EC2, the splitting tensile strength $\left(f_{c t m, s p}\right)$ can be related to $f_{c k}$ by the following expression:

$f_{c t m, s p}=(1 / 0.9) *\left[0.3 \cdot\left(f_{c k}\right)^{2 / 3}\right]$

Thus the predicted splitting tensile strength for reference concrete should be around 3.53 MPa. The observed tensile strength $(3.47 \mathrm{MPa})$ is almost the same as the predicted value for the 28-day splitting tensile strength of the reference concrete.

Table 8. Environmental exposure classes (EN 206).

\begin{tabular}{clc}
\hline Class & \multicolumn{1}{c}{ Environmental exposure condition } & Subclasses \\
\hline XO & $\begin{array}{l}\text { No risk of corrosion (inside buildings with } \\
\text { very low air humidity) }\end{array}$ & 1 \\
XC & $\begin{array}{l}\text { Corrosion of the reinforcement induced by } \\
\text { carbonation }\end{array}$ & 4 \\
XD & $\begin{array}{l}\text { Corrosion of the reinforcement induced by } \\
\text { chlorides other than from sea water }\end{array}$ & 3 \\
XS & $\begin{array}{l}\text { Corrosion of the reinforcement induced by } \\
\text { chlorides from sea water }\end{array}$ & 3 \\
XF & $\begin{array}{l}\text { Freeze-thaw attack with or without de-icing } \\
\text { agents }\end{array}$ & 4 \\
XA & Chemical attack & 3 \\
\hline
\end{tabular}


A plot of the cubic compressive strength versus tensile strength for different concrete specimens is presented in Figure 11a. The solid line is extrapolated from data obtained using the EC2 expression for concrete with various types and amounts of PET-aggregate. From the figure, it can be concluded that the tensile strength of the reference concrete and the concretes incorporating PP and 5\% and 10\% of $\mathrm{PF}$ are almost the same as or slightly lower than the value predicted by EC2. On the other hand, the tensile strength of concrete containing PC at all substitution levels and concrete containing $15 \% \mathrm{PF}$ is considerably lower than the value obtained from EC2. The deviations of the experimental results from the results established in EC 2 are possibly due to the higher w/c ratios, the poorer workability and greater porosity of this type of concrete compared with the other concrete mixes.

According to EC2, the relationship between mean cubic compressive strength $\left(f_{\mathrm{cm}}\right)$ and flexural strength $\left(f_{\mathrm{ct}, \mathrm{fl}}\right)$ of concrete below class C50/60 is expressed by ${ }^{33}$ :

$f_{\mathrm{ct}, \mathrm{fl}}(\mathrm{MPa})=1.5\left[0.3 \times\left(f_{\mathrm{cm}} / 1.25\right)^{2 / 3}\right]$, where $f_{\mathrm{cm}}$ is in $\mathrm{MPa}$

Thus, based on this relationship, concrete with a cubic compressive strength of $43 \mathrm{MPa}$ should have a flexural

Table 9. Some concrete subclasses and comparison of the relevant properties of these classes with concrete prepared in this investigation.

\begin{tabular}{|c|c|c|c|c|c|c|}
\hline Class & $\begin{array}{c}\text { Environmental } \\
\text { exposure condition }\end{array}$ & $\begin{array}{c}\text { Where exposure classes may } \\
\text { occur }\end{array}$ & $\begin{array}{l}\text { Maximum } \\
\text { W/C }\end{array}$ & $\begin{array}{l}\text { Minimum } \\
\text { strength } \\
\text { class* }\end{array}$ & $\begin{array}{l}\text { Minimum } \\
\text { cement content } \\
\left(\mathrm{kg} \cdot \mathrm{m}^{-3}\right)\end{array}$ & $\begin{array}{l}\text { Minimum air } \\
\text { volume }(\%)\end{array}$ \\
\hline $\mathrm{XO}$ & No risk of corrosion & $\begin{array}{l}\text { Inside buildings with very low } \\
\text { air humidity }\end{array}$ & - & - & - & \\
\hline $\mathrm{XC1}$ & Dry or permanently wet & $\begin{array}{l}\text { Inside buildings with low air } \\
\text { humidity }\end{array}$ & 0.65 & $20 / 25$ & 260 & \\
\hline $\mathrm{XC} 2$ & Wet, rarely dry & $\begin{array}{c}\text { Water retaining structures } \\
\text { Foundations }\end{array}$ & 0.60 & $25 / 30$ & 280 & \\
\hline $\mathrm{XC} 3$ & Moderate humidity & $\begin{array}{l}\text { Inside buildings with moderate/ } \\
\text { high air humidity } \\
\text { External structures sheltered } \\
\text { from rain }\end{array}$ & 0.55 & $30 / 37$ & 280 & \\
\hline $\mathrm{XC} 4$ & Cyclic wet-dry & $\begin{array}{l}\text { External structures exposed to } \\
\text { rain water }\end{array}$ & 0.50 & $30 / 37$ & 300 & \\
\hline XD1 & Moderate humidity & $\begin{array}{l}\text { Structures exposed to direct } \\
\text { spray containing chlorides }\end{array}$ & 0.55 & $30 / 37$ & 300 & \\
\hline $\mathrm{XD} 2$ & Wet, rarely dry & $\begin{array}{c}\text { Swimming pools } \\
\text { Structures exposed to industrial } \\
\text { waters with } \mathrm{Cl}^{-}\end{array}$ & 0.55 & $30 / 37$ & 300 & \\
\hline $\mathrm{XD} 3$ & Cyclic wet-dry & $\begin{array}{l}\text { Parts of bridges } \\
\text { Pavements } \\
\text { Car park slabs } \\
\end{array}$ & 0.45 & $35 / 45$ & 320 & \\
\hline $\mathrm{XS} 1$ & $\begin{array}{l}\text { Exposed to airborne } \\
\text { salt but not in direct } \\
\text { contact with sea water }\end{array}$ & $\begin{array}{l}\text { Structures near to or on the } \\
\text { coastal area }\end{array}$ & 0.50 & $30 / 37$ & 300 & \\
\hline $\mathrm{XF} 1$ & $\begin{array}{c}\text { Moderate water } \\
\text { saturation, without de- } \\
\text { icing salts }\end{array}$ & $\begin{array}{l}\text { Vertical surfaces exposed to rain } \\
\text { and freezing }\end{array}$ & 0.55 & $30 / 37$ & 300 & \\
\hline $\mathrm{XF} 2$ & $\begin{array}{l}\text { Moderate water } \\
\text { saturation, with de- } \\
\text { icing salts }\end{array}$ & $\begin{array}{l}\text { Vertical surfaces of road } \\
\text { structure exposed to freezing } \\
\text { and airborne de-icing salts }\end{array}$ & 0.55 & $25 / 30$ & 300 & 4 \\
\hline $\mathrm{XF} 3$ & $\begin{array}{l}\text { High water saturation, } \\
\text { without de-icing salts }\end{array}$ & $\begin{array}{l}\text { Horizontal surfaces exposed to } \\
\text { rain and freezing }\end{array}$ & 0.50 & $30 / 37$ & 320 & 4 \\
\hline Ref & & & 0.53 & 43 & 350 & \\
\hline PC5 & & & 0.59 & 31 & 350 & \\
\hline $\mathrm{PC} 10$ & & & 0.63 & 22 & 350 & \\
\hline $\mathrm{PC} 15$ & & & 0.70 & 15 & 350 & \\
\hline PF5 & & & 0.56 & 36 & 350 & \\
\hline PF10 & & & 0.57 & 31 & 350 & \\
\hline PF15 & & & 0.59 & 25 & 350 & \\
\hline PP5 & & & 0.53 & 38 & 350 & \\
\hline PP10 & & & 0.52 & 37 & 350 & \\
\hline PP15 & & & 0.52 & 33 & 350 & \\
\hline
\end{tabular}

*Cylinder/cube concrete strength class $\left(\mathrm{N} / \mathrm{mm}^{2}\right)$ based on cement of strength class 32.5 . 
strength of 4.76 MPa. The flexural strength observed for the reference concrete, i.e. $4.74 \mathrm{MPa}$, is almost equal to the value predicted by EC2.

A plot of the cubic compressive strength versus flexural strength for different concrete specimens is presented in Figure 11b. The solid line is extrapolated from data obtained using the EC2 expression for concrete with various types and amounts of PET-aggregate, which is calculated from the experimental compressive strength. Unlike the splitting tensile strength, the flexural strength of the reference concrete and the concrete incorporating plastic behaves according to EC2.

\subsection{Analysis of results using European standard EN 206}

The European Standard EN 206 defines the classes of concrete according to various environmental conditions and recommends relevant technical limits for concrete composition and strength class ${ }^{34,35}$. Again, each class has various subclasses. The definition of the various classes is presented in Table 8.

Table 9 lists some relevant subclasses, plus the technical limits required for durable concrete in terms of maximum water-cement ratio (w/c), minimum 28-day characteristic compressive strength (strength class), and minimum air volume, if any, along with the properties of the concrete prepared in this research.

Although more investigation is necessary, from Table 9 it can be concluded that concrete mixes prepared with $5 \%$ substitution of NA by PC, $5 \%$ and $10 \%$ substitution of NA by $\mathrm{PF}$ and $15 \%$ substitution of $\mathrm{PP}$ meet the requirements of concrete subclasses XC1, XC2 and possibly XF2. Furthermore, concrete containing $15 \%$ PF meets the specifications for $\mathrm{XC} 1$. Concrete prepared by substituting $5 \%$ and $10 \%$ of NA by PP meets all concrete subclasses' requirements indicated in Table 9 except subclass XD3, due to not enough strength, and some other classes due to high water to cement ratio. However, concrete mixes with $10 \%$ and $15 \%$ PC do not conform to any of the classes mentioned in this table. This is mainly because of the very poor workability of these concrete mixes and their high w/c

\section{References}

1. Magrinho A, Didelet F and Semião V. Municipal solid waste disposal in Portugal. Waste Management. 2006; 26(12):14771489. PMid:16713239. http://dx.doi.org/10.1016/j. wasman.2006.03.009

2. Raadal HL and Hansen OJ. Recycling of plastic in the Drammen region: Assessment of landfill, energy recovery and recycling of plastic packaging waste (in Norwegian). Norway: Ostfold Research Foundation; 1999. OR45.99.

3. Eriksson E and Olund G. Recycling, energy recovery or landfill? Environmental analysis of producer responsibility for plastic packaging (in Swedish). Gothenburg: Department of Technical Environmental Planning, Chalmers University of Technology; 1999.

4. Nyland CA, Modahl IS, Raadal HL and Hansen OJ. Application of LCA as a decision-making tool for waste management systems: Material flow modelling. International Journal of values. In this sense, the addition of a superplasticizer to improve the workability performance of concrete containing plastic aggregate may be an interesting option to improve the properties and therefore these types of concrete will probably meet various subclasses, defined in Table 9.

\section{Conclusions}

The results of this investigation can be summarised as:

- The development of compressive strength of concrete containing all types of PET-aggregates is similar to conventional concrete, though this incorporation significantly lowers the compressive strength of the resulting concrete;

- The early compressive strength gain (0 to 7 days) relative to the strength determined after 91 days of curing for most of the concretes containing PET-aggregates is higher than that observed for conventional concrete;

- The incorporation of PET-aggregate in concrete increases the toughness behaviour. For a given amount of PET addition, this order is: $\mathrm{PC}>\mathrm{PF}>\mathrm{PP}$, which indicates that adding large-flake PET-aggregate can have more effect on the improvement of the toughness behaviour of resulting concrete than the two other fractions; and

- The splitting tensile and flexural strength of concrete containing any type of PET-aggregate are proportional to its loss of compressive strength. This preliminary study has thus shown that the accepted and assumed relationships between engineering properties and compressive strength, as used in European design codes, can be applied to concrete containing PETaggregate.

\section{Acknowledgements}

The authors are grateful to Cristina Barbosa, from Selenis Inc, Portugal, for providing valuable information on plastic waste. The financial assistance of FCT and ICIST, Portugal, is also gratefully acknowledged.

Life Cycle Assessment. 2003; 8(6):331-336. http://dx.doi. org/10.1007/BF02978506

5. Albano C, Camacho N, Hernandez M, Matheus A and Gutierrez A. Influence of content and particle size of waste pet bottles on concrete behaviour at different $\mathrm{w} / \mathrm{c}$ ratios. Waste Management. 2009; 29(10):2707-2716. PMid:19525104. http:// dx.doi.org/10.1016/j.wasman.2009.05.007

6. Akcaozoglu S, Atis CD and Akcaozoglu K. An investigation on the use of shredded waste PET bottles as aggregate in lightweight concrete. Waste Management. 2010; 32(2):285290. PMid:19853433. http://dx.doi.org/10.1016/j. wasman.2009.09.033

7. Frigione M. Recycling of PET bottles as fine aggregate in concrete. Waste Management. 2010; 30(6):11011106. PMid:20176466. http://dx.doi.org/10.1016/j. wasman.2010.01.030

8. Hannawi K, Kamali-Bernard S and Prince W. Physical and mechanical properties of mortars containing PET and PC 
waste aggregates. Waste Management. 2010; 30(11):23122320. PMid:20417085. http://dx.doi.org/10.1016/j. wasman.2010.03.028

9. Kim SB, Yi NH, Kim HY, Kim JHJ and Song YC. Material and structural performance evaluation of recycled PET fibre reinforced concrete. Cement and Concrete Composites. 2010; 32(3):232-240. http://dx.doi.org/10.1016/j. cemconcomp.2009.11.002

10. Ferreira L, De Brito J and Saikia N. Influence of curing conditions on the mechanical performance of concrete containing recycled plastic aggregate. Construction and Building Materials. 2012; 36:196-204. http://dx.doi. org/10.1016/j.conbuildmat.2012.02.098

11. Silva RV, De Brito J and Saikia N. Influence of the curing conditions on the durability related performance of concrete with selected recycled waste aggregates. Cement and Concrete Composites. 2013; 35(1):23-31.

12. Marzouk OY, Dheilly RM and Queneudec M. Valorisation of postconsumer waste plastic in cementitious concrete composites. Waste Management. 2007; 27(2):310-318. PMid:16730969. http://dx.doi.org/10.1016/j.wasman.2006.03.012

13. Kou SC, Lee G, Poon CS and Lai WL. Properties of lightweight aggregate concrete prepared with PVC granules derived from scraped PVC pipes. Waste Management. 2009; 29(2):621628. PMid:18691863. http://dx.doi.org/10.1016/j. wasman.2008.06.014

14. Naik TR, Singh SS, Huber CO and Brodersen BS. Use of postconsumer waste plastics in cement-based composites. Cement and Concrete Research. 1996; 26(10):1489-1492. http://dx.doi. org/10.1016/0008-8846(96)00135-4

15. Panyakapo $\mathrm{P}$ and Panyakapo $\mathrm{M}$. Reuse of thermosetting plastic waste for lightweight concrete. Waste Management. 2008; 28(9):1581-1588. PMid:17910913. http:// dx.doi.org/10.1016/j.wasman.2007.08.006

16. Al-Manaseer AA and Dalal TR. Concrete containing plastic aggregates. Concrete International. 1997; 19(8):47-52.

17. Ismail ZZ and Al-Hashmi EA. Use of waste plastic in concrete mixture as aggregate replacement. Waste Management. 2008; 28(11):2041-2047. PMid:17931848. http:// dx.doi.org/10.1016/j.wasman.2007.08.023

18. Kan A and Demirboga R. A novel material for lightweight concrete production. Cement and Concrete Composites. 2009; 3(7):489-495. http://dx.doi.org/10.1016/j. cemconcomp.2009.05.002

19. Mounanga P, Gbongbon W, Poullain P and Turcry P. Proportioning and characterization of lightweight concrete mixtures made with rigid polyurethane foam wastes. Cement and Concrete Composites. 2008; 30(9):806-814. http://dx.doi. org/10.1016/j.cemconcomp.2008.06.007

20. Fraj AB, Kismi M and Mounanga P. Valorization of coarse rigid polyurethane foam waste in lightweight aggregate concrete. Construction and Building Materials. 2010; 24(6):1069-1077. http://dx.doi.org/10.1016/j.conbuildmat.2009.11.010

21. Asokan P, Osmani M and Price ADF. Improvement of the mechanical properties of glass fibre reinforced plastic waste powder filled concrete. Construction and Building Materials. 2010; 24(4):448-460. http://dx.doi.org/10.1016/j. conbuildmat.2009.10.017

22. Saikia $\mathrm{N}$ and de Brito J. Use of plastic waste aggregate in concrete: A review. Construction and Building
Materials. 2012; 34:385-401. http://dx.doi.org/10.1016/j. conbuildmat.2012.02.066

23. DuPont. Innovation in Plastics, Polymers \& Resins: From engineering thermoplastics to biobased polymers to films and parts. Available from: <http://www.engineeringpolymers.com/ epbb/ch12.html>. Accessed in: 08/02/2011).

24. The Engineering ToolBox. Thermal conductivity of some common materials and gases - insulation, aluminum, asphalt, brass, copper, steel and many more. Available from: <http:// www.engineeringtoolbox.com/thermal-conductivity-d_429. html >. Accessed in: 09/02/2011.

25. The Engineering ToolBox. A comprehensive list of some common solids as brick, cement, glass and many more - and their specific heats - imperial and SI units. Available from: <http://www.engineeringtoolbox.com/specific-heatsolids-d_154.html>. Accessed in: 09/02/2011.

26. Saikia $\mathrm{N}$ and de Brito J. Use of some solid waste material as aggregate, filler or fiber in cement mortar and concrete. In: Wythers MC, editor. Advances in Material Science Research. Nova Science Publishers; 2010. v. 3, p. 65-116.

27. Choi YW, Moon DJ, Chung JS and Cho SK. Effects of waste PET bottles aggregate on the properties of concrete. Cement and Concrete Research. 2005; 35(4):776-781. http://dx.doi. org/10.1016/j.cemconres.2004.05.014

28. Choi YW, Moon DJ, Kim YJ and Lachemi M. Characteristics of mortar and concrete containing fine aggregate manufactured from recycled waste polyethylene terephthalate bottles. Construction and Building Materials. 2009; 23(8):2829-2835. http://dx.doi.org/10.1016/j.conbuildmat.2009.02.036

29. Silva DA, Betioli AM, Gleize PJP, Roman HR, Gomez LA and Ribeiro JLD. Degradation of recycled PET fibres in Portland cement-based materials. Cement and Concrete Research. 2005; 35:1741-1746. http://dx.doi.org/10.1016/j. cemconres.2004.10.040

30. Jingfu KMC and Jiang Y. Improvement of crackingresistance and flexural behavior of cement-based materials by addition of rubber particles. Journal of Wuhan University of Technology - Materials Science Edition. 2008; 23(4):579-583. http://dx.doi.org/10.1007/s11595-006-4579-8

31. Li G, Stubblefield MA, Garrick G, Eggers J, Abadie C and Huang B. Development of waste tire modified concrete. Cement and Concrete Research. 2004; 34(12):2283-2289. http://dx.doi. org/10.1016/j.cemconres.2004.04.013

32. Euro code - EC. Euro code 2: Design of concrete structures - Part 1-1: General rules and rules for buildings. Brussels: CEN; 2004.

33. Paine KA, Collery DJ and Dhir RK. Strength and deformation characteristics of concrete containing coarse recycled and manufactured aggregates. In: Proceedings of the 11th International Conference on Non-conventional Materials and Technologies; 2009; Bath. Available from: <www.bath. ac.uk/ace/uploads/BRE/.../papers/Paper\%2084.pdf>. Access in: $27 / 08 / 2012$.

34. Troli R and Collepardi M. Technical contradictions in the European norm EN 206 for concrete durability. In: Role of concrete in sustainable development. London: Thomas Telford Limited; 2003. p. 665-674. Available from: <www.inti.gov. ar/cirsoc/pdf/ tecnologia_hormigon/europeNorm206.pdf>. Accessed in: 27/08/2012.

35. European Standard - EN. EN 206: Specifications, performance, production, and conformity: Concrete-Part 1. EN; 2000. 